\title{
RESENHA:
}

EXPERIMENTAÇÕES

EM DIAMANTINA:

A PRÁTICA DO IPHAN EM UMA CIDADE TOMBADA. GONÇALVES, CRISTIANE SOUZA.

SÃO PAULO: EDITORA UNIFESP, 2019. 256P.

MAÍRA DE CAMARGO BARROS, UNIVERSIDADE FEDERAL DE SÃO PAULO, SÃO PAULO, SÃO PAULO, BRASIL

Mestranda no Programa de Pós-Graduação em História da Universidade Federal de São Paulo (UNIFESP). Arquiteta urbanista pela Universidade Estadual de Campinas (UNICAMP).

Orcid: https://orcid.org/0000-0001-9754-0959

E-mail: arqmairacbarros@gmail.com

RECEBIDO

DOI

25/09/2020

APROVADO

http://doi.org/10.11606/issn.1980-4466.v16i31p383-390

$17 / 06 / 2021$ 


\section{RESENHA: EXPERIMENTAÇÕES EM DIAMANTINA: A PRÁTICA DO IPHAN EM UMA CIDADE TOMBADA. GONÇALVES, CRISTIANE SOUZA. SÃO PAULO: EDITORA UNIFESP, 2019. 256P. MAÍRA DE CAMARGO BARROS}

A constituição do órgão de preservação federal brasileiro, as políticas de salvaguarda por ele adotadas e os personagens que dão vida a essa trajetória têm sido objetos de pesquisa há, pelo menos, três décadas. No entanto, apesar do crescente número de publicações relacionadas à temática, nota-se que quanto mais se pesquisa, mais há a descobrir. As abordagens, os documentos encontrados em cada nova obra não esgotam o tema, apenas o tornam cada vez mais interessante e complexo.

Analisar as ações do Instituto do Patrimônio Histórico e Artístico Nacional (Iphan), a partir de sua fundação, em 1937, faz-se necessário para compreender as predileções e apagamentos promovidos, desde então, pela instituição frente à memória e ao patrimônio nacional.

Neste sentido, o livro Experimentações em Diamantina: a prática do Iphan em uma cidade tombada, da arquiteta Cristiane Souza Gonçalves, é, sem dúvida, um importante exemplo de pesquisa. Através de uma linguagem erudita, porém de fácil compreensão, a autora apresenta-nos e questiona uma série de documentos encontrados sobre as primeiras décadas de atuação do Iphan na cidade de Diamantina, localizada na região centro-norte de Minas Gerais.

Fruto de sua tese de doutoramento, desenvolvida na Faculdade de Arquitetura e Urbanismo da Universidade de São Paulo (FAU-USP), a publicação de 256 páginas divide-se em quatro capítulos: Diamantina: breve relato de sua formação; Primeiras décadas: Minas é o Brasil; A prática do Iphan em uma cidade tombada (1938-1967); e Um capítulo à parte: obras modernas no antigo arraial. Neles, a pesquisadora apoia-se em autores clássicos, trazendo uma reflexão acerca do processo de institucionalização da preservação do patrimônio no Brasil em âmbito federal, a partir da análise de situações ocorridas na chamada "fase heroica” em Diamantina. 


\section{Conforme destaca Leonardo Castriota, professor titular da}

Universidade Federal de Minas Gerais (UFMG), no prefácio do livro, a pesquisa de Cristiane Gonçalves - já iniciada com sua dissertação de mestrado, que também se tornou livro: Restauração Arquitetônica: a experiência do Sphan em São Paulo (1937-1975) ${ }^{1}$ - soma-se às significativas contribuições trazidas pelo mestrado de Silvana Rubino ${ }^{2}$ e pelas teses de doutoramento de Maria Cecilia Londres Fonseca ${ }^{3}$, Marcia Regina Romeiro Chuva ${ }^{4}$,

1 GONÇALVES, Cristiane Souza. Restauração arquitetônica: A Experiência do Sphan em São Paulo (1937-1975). São Paulo: FAPESP - Annablume, 2007. p. 213.

2 Silvana Barbosa Rubino é graduada em Ciências Sociais pela Universidade de São Paulo em 1982, mestre pela Universidade Estadual de Campinas em Antropologia Social em 1992, com a dissertação As fachadas da história. As origens, a criação e os trabalhos do Sphan, 1936-1967; e doutora em Ciências Sociais pela mesma universidade em 2002, com a tese: Rotas da modernidade: trajetória, campo e história na atuação de Lina bo Bardi, 1947-1968. Estagiou em seu pós-doutorado na École des Hautes Études en Sciences Sociales, em Paris, sob a supervisão de Afrânio Garcia, entre 2012-2013, e na área de História sob a supervisão de Monica Raisa Schpun, em 2017. É professora do Departamento de História da Universidade Estadual de Campinas desde 2003, assumindo diversos cargos de coordenação e chefia naquele departamento. Por oito anos foi conselheira do Conselho de Defesa do Patrimônio Histórico, Artístico, Arqueológico e Turístico do Estado de São Paulo (Condephaat). Informações colhidas em: Currículo Lattes (2020).

3 Maria Cecília Londres Fonseca graduou-se em Letras pela Pontifícia Universidade Católica do Rio de Janeiro. É mestre em Teoria da Literatura pela Universidade Federal do Rio de Janeiro e doutora em Sociologia pela Universidade de Brasília. Tem vasta atuação na área do patrimônio, como: pesquisadora do Centro Nacional de Referência Cultural-CNRC (1976-1979), coordenadora de projetos da Fundação Nacional Pró-Memória (1979-1990), assessora do Ministério da Cultura (1995-1998) e coordenadora de Políticas da Secretaria de Patrimônio, Museus e Artes Plásticas do Ministério da Cultura (1999-2001). Foi membro do Grupo de Trabalho do Patrimônio Imaterial (1998-200o) e representou o Brasil nas reuniões de peritos internacionais para a elaboração da Convenção para a Salvaguarda do Patrimônio Cultural Imaterial, entre os anos de 2002 e 2003, na UNESCO. Desde 2004, participa do Conselho Consultivo do Patrimônio Cultural e desde 2005 é sócia correspondente do Instituto Histórico e Geográfico Brasileiro (IHGB). Ainda, é autora do livro O Patrimônio em processo, lançado pela Universidade Federal do Rio de Janeiro. Informações contidas em: Editora UFRJ (2020).

4 Márcia Regina Romeiro Chuva formou-se em História pela Universidade Federal do Rio de Janeiro (UFRJ) em 1985 e obteve o título de doutora pela Universidade Federal Fluminense (UFF) em 1998, com a tese que depois virou livro: Os arquitetos da memória: a construção do patrimônio histórico e artístico nacional no Brasil - anos 30 e 40. De 1985 a 2009 trabalhou no Instituto do Patrimônio Histórico e Artístico Nacional (Iphan), onde assumiu diversos cargos de coordenação. Desde 2009, é professora Associada da Universidade Federal do Estado do Rio de Janeiro (UNIRIO). A partir de 2010 também atua como professora no Programa de Pós-Graduação em História da UNIRIO e no Mestrado Profissional em Patrimônio Cultural do Iphan. Coordena a equipe brasileira do projeto European Colonial Heritage Modalities in Entangled Cities (ECHOES) Horizon 2020, integrado ao Centro de Estudos Sociais da Universidade de Coimbra. Para mais informações: Currículo Lattes (2020). 
Mariza Veloso Motta Santos 5 , José Reginaldo Gonçalves ${ }^{6}$, entre outros.

Vale lembrar que a cidade de Diamantina teve seu conjunto urbano tombado em 1938, pelo então Sphan, que juntamente com outras cinco localidades - Ouro Preto, Tiradentes, Mariana, São João Del Rey e Serro (p. 111) - formam um importante acervo urbano edificado.

Cristiane Gonçalves elucida, de maneira singular, nos capítulos dois e três, diversos processos que solicitam autorização para reformas, demolições e construção de novos imóveis no município, além de documentos trocados entre o $3^{\circ}$ Distrito - como era chamada, à época, a subsede do órgão em Minas Gerais - e a sede do Rio de Janeiro, capitaneados por um longo período de pesquisas.

A partir destas fontes documentais é possível compreender as relações de poder dentro do órgão federal, quais os personagens mais relevantes naquele contexto e como se deu a política de preservação nos primeiros anos de existência do Iphan. Elas ainda explicitam o grande volume de solicitações, a morosidade e a centralidade nas respostas do órgão federal.

Nota-se por exemplo que Sylvio de Vasconcelos, um notável estudioso da arquitetura mineira, formado engenheiro-arquiteto pela Escola de Arquitetura da Universidade Federal de Minas Gerais (EAUFMG) no ano de 1944 (p. 107) e diretor do $3^{\circ}$ Distrito naquele período, tinha pouquíssima autonomia na avaliação e resolução das ocorrências, mesmo com o amplo trabalho desenvolvido

5 Mariza Veloso Motta Santos graduou-se em Ciências Sociais pela Universidade de Brasília em 1977, é mestre (1981) e doutora (1992) em Antropologia pela mesma universidade, quando produziu a tese: O Tecido do tempo: a idéia de patrimônio cultural no Brasil. Em 1993, tornou-se professora do Instituto Rio Branco - Ministério das Relações Exteriores. Desde 1996 é também professora da Universidade de Brasília (UnB). Entre 2002 e 2003 desenvolveu pós-doutorado na New York University (NYU) em Estudos Urbanos. Informações contidas em: Currículo Lattes (2020).

6 José Reginaldo Santos Gonçalves, em 1975, formou-se em Ciências Sociais pela Universidade Federal do Rio de Janeiro (UFRJ). Tornou-se mestre em Antropologia Social pelo PPGAS do Museu Nacional da Universidade Federal do Rio de Janeiro, em 1980. É PhD em Antropologia Cultural pela Universidade de Virginia, Charlottesville, Estados Unidos, em 1989. Possui pós-doutorado na Brown University, Providence, Rhode Island, Estados Unidos, em 200o. Foi também Fulbright Visiting Scholar na Yale University e na New Haven, Connecticut, também nos Estados Unidos, na condição de Professor Sênior CAPES / Fulbright (MacMillan Center for International and Area Studies) em 2006. Ainda em 2016, esteve como professor visitante no Graduate Center da City University of New York, Estados Unidos. É professor de Antropologia Cultural na UFRJ e pesquisador associado do Programa Avançado de Cultura Contemporânea (PACC / UFRJ). Autor de alguns livros, entre eles: A retórica da perda: os discursos do patrimônio cultural no Brasil (2002) e organizador de A experiência etnográfica: antropologia e literatura do século XX (2011). Informações em: Currículo Lattes (2020). 
à frente do distrito, com a produção de inventários, catalogações e pesquisas históricas. A maioria das solicitações eram enviadas para a sede do Sphan no Rio de Janeiro para que lá fossem analisadas pelo corpo técnico local.

Em parte significativa dos processos contemplados por Gonçalves, as soluções de reforma dos imóveis apresentadas pelos solicitantes não eram apenas rejeitadas pelos analistas, mas, curiosamente, era-lhes enviada nova proposta, adequando as edificações aos padrões considerados corretos em forma e estilo pelo órgão.

As proposituras de alterações de projeto vinham com desenhos que, segundo a autora, nem sempre eram interessantes esteticamente. Eram retirados elementos decorativos ou arquitetônicos tidos como espúrios, ou seja, elementos "não coloniais", considerado naquele período o estilo arquitetônico símbolo do estado-nação. As intervenções deveriam ser sempre com materiais contemporâneos, o que revela "um propósito maior de redesenho da história a partir da atuação institucional” (p. 32), priorizando-se determinadas características arquitetônicas em detrimento de outras.

Neste sentido, a autora destaca, ao longo de toda a obra, a importância do arquiteto modernista Lucio $\operatorname{Costa}^{7}$ - que compunha o grupo que fomentou a formação do Sphan, desde a década de 1920, e tornou-se funcionário de carreira do órgão, após sua criação, através do Decreto-lei 25/1937 ${ }^{8}$. Suas ações foram fundamentais para a definição da corrente preservacionista adotada pelo órgão, dada sua participação, ou até mesmo imposição, de soluções arquitetônicas enviadas aos diamantinenses e nas resoluções de problemáticas enfrentadas na cidade que envolvessem a temática da salvaguarda.

7 Lúcio Ribeiro da Costa (1902-1998) Chegou ao Brasil em 1916, após ter nascido na França, onde seu pai era diplomata, e estudado na Inglaterra e Suíça. Em 1923, formou-se em Arquitetura na Escola Nacional de Belas Artes (ENBA), localizada na cidade do Rio de Janeiro. Anos mais tarde, após a consolidação da ditadura varguista, foi nomeado diretor da mesma instituição. Sua carreira se iniciou no neocolonial, migrando para o modernismo. Articulou a vinda do arquiteto francês Le Corbusier ao país em 1936, para dar apoio no desenvolvimento do projeto da sede do Ministério da Educação e Cultura (MEC). Em 1937, assumiu a direção da Divisão de Estudos de Tombamento do recém-inaugurado Serviço do Patrimônio Histórico e Artístico Nacional (Sphan). permanecendo na instituição até sua aposentadoria em 1972, tendo posição de destaque e de tomada de decisões. Foi também autor do Plano Piloto de Brasília, significativa contribuição para o urbanismo moderno. Informações contidas em: CPDOC (2020).

8 1937: Decreto-lei 25/1937 foi publicado no dia 30 de novembro de 1937, assinado pelo então presidente Getúlio Vargas, determinando a criação do Serviço do Patrimônio Histórico e Artístico Nacional (Sphan), após longa articulação de diversos entusiastas ligados ao movimento moderno, como: Rodrigo Mello Franco de Andrade, Lucio Costa e Mário de Andrade. 
Por vezes, o próprio diretor da instituição, Rodrigo Melo Franco de Andrade ${ }^{9}$, respondia às solicitações, atuação exemplificada através de trecho em que Gonçalves expõe extensa carta enviada, em maio de 1938, ao então prefeito de Diamantina, Joubert Guerra, esclarecendo-lhe algumas dúvidas quanto ao recente tombamento da cidade (p. 131). Segundo a autora, o documento traz as diretrizes gerais no que diz respeito às políticas de preservação adotadas pelo órgão nos anos seguintes.

Ainda, no último capítulo, são apresentadas ao leitor as obras de arquitetura moderna produzidas na cidade, sendo algumas de autoria desconhecida e outras contratadas por Juscelino Kubitschek - nascido em Diamantina e, naquele período, governador de Minas Gerais - a Oscar Niemeyer. O arquiteto moderno foi responsável por projetar uma sede social para a Praça de Esportes, o Hotel Tijuco e uma escola primária que se chamaria "Júlia Kubitschek", ressaltando a parceria entre o político e o arquiteto que viria a ser coroada com a construção de Brasília, em 1960.

A autora a divide a metodologia aplicada na pesquisa em duas partes, chamando-as de exame teórico e exame empírico. Na primeira, ela se debruçou sobre estudos já produzidos sobre o Iphan; teóricos como Cesare Brandi ${ }^{10}$, Giovanni Carbonara ${ }^{11}$, John Ruskin ${ }^{12}$, entre outros; as

9 Rodrigo Melo Franco de Andrade (1898-1969): após temporada de estudos em Paris, Andrade retornou ao país e iniciou o curso de direito, passando por diferentes instituições nas cidades do Rio de Janeiro, Belo Horizonte e São Paulo. Em 1921, enveredou pela carreira jornalística, a partir do jornal O Dia, atuando em diferentes periódicos. A partir de 1922, começou a se interessar pelo movimento moderno, dada sua amizade com Mário de Andrade. Nos anos seguintes, atuou na gestão pública e como advogado. Em 1937, assume a direção do Sphan por indicação de Mário, permanecendo no cargo até sua aposentadoria em 1967, sendo protagonista da chamada "fase heroica" da instituição. Informações: Portal do Iphan (2020).

10 Cesare Brandi (1906-1988), teórico italiano, responsável pela fundamentação do chamado "restauro crítico", sendo importante referência para o restauro de objetos de arte e arquitetura na atualidade. Esse princípio traz as ações de salvaguarda para o campo da ciência, desvinculando-a do empirismo. Foi fundador e diretor do Instituto Central de Restauro em Roma além de consultor da UNESCO. Para mais informações: KÜHL, 2007.

11 Giovanni Carbonara (n. 1942): arquiteto italiano foi, entre 1995 e 2013, professor e diretor da Pós-Graduação para o Estudo e Restauro da Universidade La Sapienza, sendo considerado grande teórico do patrimônio na atualidade, tendo uma série de publicações sobre a temática. Sua produção aborda intervenções contemporâneas em sítios históricos, restauro urbano, balizados nos princípios do restauro crítico-conservativo. Para mais informações: ALMEIDA, 2019.

12 John Ruskin (1819-1900): teórico inglês, foi aluno e professor na Universidade de Oxford. Defensor da preservação dos monumentos históricos, Ruskin foi o fundador do movimento "antirrestauração" que para ele seria a derrocada de determinado edifício. Defendia que as construções deveriam ser conservadas, entendendo-se conservação como uma manutenção permanente, assim nunca precisariam de restauros. Para informações adicionais ver: MONTEIRO, 2012. 
cartas patrimoniais; frutos de encontros voltados ao debate e a troca de experiências sobre a prática da preservação. Já no exame empírico, Gonçalves inclui os documentos produzidos pelo próprio Iphan acerca de sua trajetória e alguns dos acervos do órgão, tais como: Arquivo Noronha Santos, Superintendência de Minas Gerais e Escritório Técnico de Diamantina.

A partir da vasta documentação encontrada nesses acervos, a autora traz uma abordagem nova, elucidativa e rica. Porém, as imagens apresentadas, muito interessantes e inéditas, são acompanhadas de legendas bastante sucintas. Estas, se mais exploradas, enriqueceriam a obra sobremaneira.

Não podemos deixar de destacar o capítulo 1 que, apesar de intitulado Diamantina: breve relato de sua formação, apresenta 37 páginas. O texto minucioso traz interessante explanação acerca da constituição da cidade de Diamantina a partir do Córrego e do Arraial do Tijuco, porém ele acaba por retardar o acesso ao conteúdo que dá nome a obra e que atrai o leitor: as experimentações em Diamantina. Possivelmente, o conteúdo apresentado poderia vir dissolvido ao longo dos demais capítulos, sendo evocado quando necessário.

Para além de sua efetiva contribuição para a compreensão da história do Iphan na chamada "fase heroica", a obra descortina personagens singulares e adentra campos da preservação voltados predominantemente à arquitetura, como o restauro científico.

Soma-se a isso, além da nova documentação trazida pela autora após ampla pesquisa, a redação do texto, de fácil compreensão, tornando a leitura convidativa; mesmo com o uso de termos técnicos inerentes a análise arquitetônica e documental; não somente a profissionais e estudantes das áreas de história, arquitetura e restauro, mais também a interessados na formação da cidade de Diamantina.

\section{REFERÊNCIAS}

ALMEIDA. Eneida de. Do monumento ao fragmento urbano: um enredo entre memória e criação. Revista Restauro, v.3, n.5, 2019. Disponível em: http://web.revistarestauro.com.br/ do-monumento-ao-fragmento-urbano-um-enredo-entre-memoria-e-criacao/. Acesso em: 8 set. 2020.

GONÇALVES, Cristiane Souza. Restauração arquitetônica: a experiência do SPHAN em São Paulo (1937-1975). São Paulo: FAPESP/Annablume, 2007. 
GONÇALVES, Cristiane Souza. Experimentações em Diamantina: a prática do Iphan em uma cidade tombada. São Paulo: Editora Unifesp, 2019.

JOSÉ Reginaldo Santos Gonçalves. In: Plataforma Lattes. Disponível em: http://lattes.cnpq. br/8759132068825242. Acesso em: 7 set. 2020.

KÜHL. Beatriz Mugayar. Cesari Brandi e a teoria da restauração. Revista Pós, São Paulo, n. 21, p. 198-211, jun. 2007. Disponível em: file://C:/Users/Ma\%C3\%ADra/Downloads/43516-Texto\%20 do\%2oartigo-51951-1-10-20120919\%2o(1).pdf. Acesso em: 8 set. 2020.

LUCIO Ribeiro da Costa. In: Centro de Pesquisa e Documentação de História Contemporânea do Brasil. Disponível em: https://cpdoc.fgv.br/producao/dossies/JK/biografias/lucio_costa. Acesso em: 8 set. 2020 .

MARCIA Regina Romeiro Chuva. In: Plataforma Lattes. Disponível em: http://lattes.cnpq. br/961324092130990o. Acesso em: 7 set. 2020.

MARIA Cecília Londres Fonseca. In: Editora UFRJ. Disponível em: http://www.editora.ufrj.br/ autor/104/maria-cecilia-londres-fonseca. Acesso em: 7 set. 2020.

MARIZA Veloso Motta Santos. In: Plataforma Lattes. Disponível em: http://lattes.cnpq. br/6351473341056488. Acesso em: 7 set. 2020.

MONTEIRO. Flávia de Azevedo. John Ruskin: teorias de preservação e suas influências na preservação do patrimônio brasileiro no início do século XX. Revista do Colóquio, v.2, n.3, 15 dez. 2012. Disponível em: https://periodicos.ufes.br/colartes/article/view/7641. Acesso em: 8 set. 2020.

RODRIGO Melo Franco de Andrade. In: Instituto do Patrimônio Histórico e Artístico Nacional. Disponível em: http://portal.iphan.gov.br/pagina/detalhes/173. Acesso em: 8 set. 2020.

SILVANA Barbosa Rubino. In: Plataforma Lattes. Disponível em: http://lattes.cnpq. br/9128168063989255. Acesso em: 7 set. 2020.

(c) (1) (2) (2) 